\title{
La dimensión emocional de los movimientos políticos populistas de S.XXI en América Latina y Europa
}

Alejandro Espí Hernández | alejandroespihernandez@gmail.com

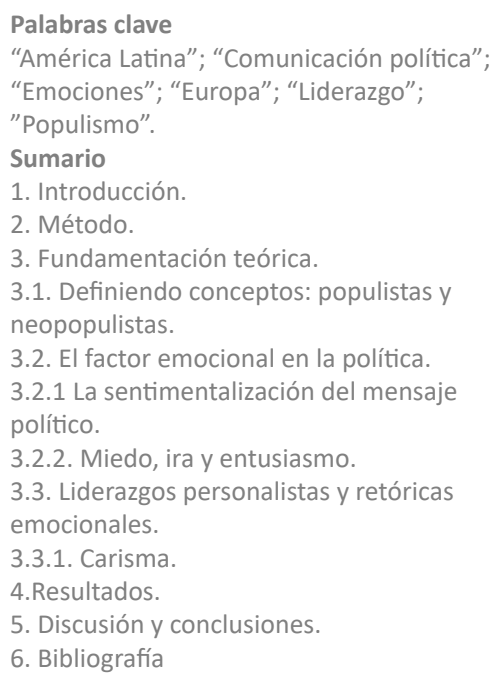

\section{Resumen}

En el presente trabajo efectuamos un análisis cualitativo relativo a los movimientos políticos del siglo XXI encuadrados bajo los términos de "populistas" o "neopopulistas" que han ido emergiendo en diferentes países de América Latina y Europa. Tratamos de demostrar la existencia de una dimensión o base emocional que esencia a la identidad de los mismos. Para ello partimos desarrollando una propuesta metodológica consistente en una clasificación operativa de características en la cual plasmamos las identidades esenciales de estos movimientos en base a cuatro dimensiones de análisis: su procedencia, su relación con la democracia representativa y, especialmente, el estilo de liderazgo y el tipo de retórica que emplean. De estas dimensiones subyace el nexo o base emocional común que constituye una esencialidad inherente a tales movimientos políticos (H1). Los resultados constatan la existencia de comportamientos y apelaciones de tipo afectivas tanto en la toma de decisiones como en las formas de comunicar y de relacionarse con los diferentes actores de las democracias representativas. En cómputo, constituyen una serie de características comunes con fuerte anclaje emocional que pormenorizamos y sustentamos empíricamente en el trabajo y que aguardan una vía común: la comunicación y forma de proyectar su idiosincrasia.

\section{Cómo citar este texto:}

Alejandro Espí Hernández (2019): La dimensión emocional de los movimientos políticos populistas de S.XXI en América Latina y Europa, en Miguel Hernández Communication Journal, n¹0 (1), pp. 101 a 121. Universidad Miguel Hernández, UMH (Elche-Alicante). DOI: http://dx.doi.org/10.21134/mhcj.v10i0.277 


\title{
The emotional dimension of the populist political movements of S.XXI in Latin America and Europe
}

\author{
Alejandro Espí Hernández| alejandroespihernandez@gmail.com
}

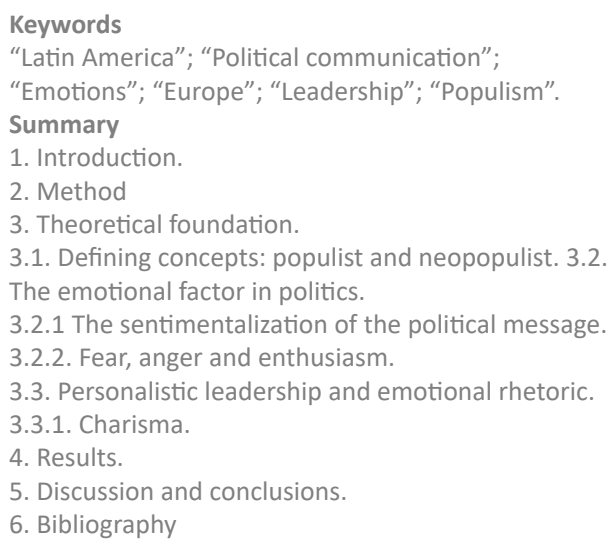

\begin{abstract}
In the present work we carry out a qualitative analysis related to the political movements of the 21 st century framed under the terms of "populists" or "neopopulists" that have been emerging in different countries of Latin America and Europe. We try to demonstrate the existence of a dimension or emotional basis that is essential to their identity. For this we start by developing a methodological proposal consisting of an operational classification of characteristics in which we shape the essential identities of these movements based on four
\end{abstract} dimensions of analysis: their origin, their relationship with representative democracy and, especially, the style of leadership and the kind of rhetoric they use. From these dimensions lies the common emotional link or basis that constitutes an essentiality inherent to such political movements (H1). The results confirm the existence of affective behaviors and appeals both in decision-making and in the ways of communicating and relating to the different actors of representative democracies. In computation, they constitute a series of common characteristics with strong emotional anchoring that we detail and support empirically in the work and that await a common path: communication and the way of projecting their idiosyncrasies..

\section{How to cite this text:}

Alejandro Espí Hernández (2019): The emotional dimension of the populist political movements of S.XXI in Latin America and Europe, in Miguel Hernández Communication Journal, nº10 (1), pp. 101 a 121. Universidad Miguel Hernández, UMH (Elche-Alicante). DOI: http://dx.doi.org/10.21134/mhci.v10i0.277 


\section{Introducción}

La inmensa mayoría de pensadores políticos de la historia, comenzando por Aristóteles y terminando por Hannah Arendt, pasando por Cicerón, Maquiavelo o Spinoza, han demostrado el rol omnipresente de las emociones en la política, aportando diferentes teorías y planteamientos filosóficos que ponen de manifiesto la conexión dada entre el poder y los procesos emocionales del ser humano. Teorías que se han demostrado certeras, porque efectivamente las emociones juegan un papel mucho mayor de lo previsto en el modo en que los individuos perciben los asuntos públicos, los evalúan y toman decisiones políticas (Forgas, 2000).

Atravesamos unas décadas de debilitamiento de los sistemas de partidos tanto en América Latina como en Europa, fundamentalmente el sur. Un periodo de crisis de la democracia representativa, donde comienza a imperar el descrédito político y, en general, una desafección marcada por fuertes crisis económicas y políticas acontecidas en ambos territorios. Sin ir más lejos, el Latinobarómetro del 2017 ilustra una reducción de la confianza hacia la democracia que se reduce a tan solo el 30\% de la ciudadanía, pese a que el 53\% de la población apoye a la democracia como régimen de gobierno. Además, sólo el 36\% de los latinoamericanos aprueba la gestión de sus gobiernos, mientras que los partidos políticos generan únicamente confianza al 15\% de la población. En el caso europeo, el último Eurobarómetro de 2018 plasma entre la ciudadanía europea un nivel de satisfacción con el funcionamiento de la democracia del 49\%. En relación a los nuevos partidos y movimientos políticos, un 53\% de los europeos dice sentir confianza a los mismos frente a los partidos tradicionales.

En un continente y otro han emergido liderazgos populistas, outsiders y anti establishment como reacción a diferentes crisis de representación política y de gobernabilidad en las democracias liberales, lo que ha provocado la erosión de la hegemonía de las fuerzas tradicionales, así como de sus modos de entender la política y lo político. Bajo este contexto han emanado dos grandes modelos o formas de hacer política: el populismo de derecha, caracterizado por efectuar un repliegue defensivo asentado en el proteccionismo y la exclusión, aplicando una política más liberal; y el populismo de izquierda, que lucha esencialmente por una redistribución de la riqueza y empoderamiento de las clases bajas o populares, con una política económica más intervencionista.

En términos generales, se viene observando una tendencia generalizada en los partidos políticos, esencialmente en los de nueva creación (emergentes), así como en candidatos outsiders, a comportarse como movimientos que rompen con los clásicos clivajes o alineaciones explicativas del comportamiento electoral, para pasar a representar estados de ánimo y clamores generales en lugar de intereses más específicos. En este sentido, los programas electorales pierden relevancia en una coyuntura de polarización y desconfianza, donde el generar lealtades partidarias se ha demostrado mucho más eficaz lográndolo desde la emoción.

Así pues, en el devenir de la historia contemporánea han ido emergiendo liderazgos en diferentes países del mundo que han sido catalogados o calificados bajo el término de "populistas", entendido como formas políticas de gestión poco convencionales que pretenden dar un mayor protagonismo y poder al "pueblo". Este modus operandi político ha sido caracterizado, fundamentalmente, por un uso personalista de la política, acompañado de un discurso sensacionalista y emotivista de fácil calado en ambientes de desafección política. Estas primeras características nos permiten vislumbrar, de entrada, el papel imprescindible que juegan las emociones para generar conexiones e identificaciones entre la ciudadanía y tales movimientos. 
En una visión más amplia, el populismo parece resultar endémico a los regímenes democráticos de masas en la medida que atraviesan crisis internas (de confianza en la representatividad) o internacionales.

Este trabajo no pretende realizar una revisión teórica sobre el término "populismo", que ya ha resultado bastante discutido por la academia y cuyo término ha sido asociado a connotaciones negativas y descalificantes. Nuestro cometido pasa por dar un paso más en el abordaje de esta forma de hacer política, tratando de encontrar los nexos emocionales comunes a tales movimientos o a sus formas de entender la gerencia del poder y que vienen emergiendo en ambos continentes desde hace décadas. Tampoco se pretende emitir juicios valorativos sobre estos diferentes tipos de liderazgos políticos, ni sobre sus causas ni sobre sus consecuencias. La presente investigación tiene como objetivo delimitar una serie de características que definen a los movimientos populistas del siglo veintiuno permitiendo ilustrar el componente emocional que existe en el trasfondo de todos ellas.

Para la consecución de nuestros objetivos partimos preguntándonos ¿están las emociones presentes en los movimientos políticos populistas?, ¿cómo integran estos movimientos las emociones en sus relatos, narrativas y formas de comunicar e interpretar la democracia? El trabajo, por consiguiente, parte con la hipótesis principal de la existencia de una base emocional común subyacente en todos los movimientos políticos denominados "populistas" o "neopopulistas".

\section{Método}

Para dar respuesta a las preguntas de investigación y la hipótesis principal, tratamos de ir más allá de análisis puramente teórico y, por ello, proponemos una clasificación operativa de características que agrupan a la mayoría de variables que definen a los movimientos políticos en base a cuatro dimensiones de análisis: 1) procedencia y contexto del movimiento, 2) su relación con la democracia representativa, 3) estilo de liderazgo, y 4) el tipo de retórica que emplean. Esta clasificación se inspira en los trabajos de Freidenberg (2007), Malamund (2010) y Hermet, Loaeza y François (2001).

Se trata de un estudio cualitativo, a modo de ejercicio analítico, que pormenoriza la esencia de estas formas de hacer política en Europa y América Latina, con una proyección afectiva que es analizada en detalle fundamentalmente en el estilo de liderazgo y el tipo de retórica empleada, pero también en los orígenes del movimiento y su relación con las democracias representativas.

Antes de proceder al análisis y los resultados, realizamos un recorrido teórico que pasa por la contextualización sobre populismo, emociones y nuevas formas políticas de comunicar que nos sirven como cimientos para comprender y construir la categorización posterior. Asimismo, sintetizamos algunos movimientos que consideramos encajarían en la categoría de populistas, o neopopulistas en función de lo teorizado y posteriormente propuesto en la clasificación operativa de características.

\section{Fundamentación teórica}

\subsection{Definiendo conceptos: populistas y neopopulistas}

Si un término ha sido teorizado y discutido en las ciencias políticas y sociológicas ha sido el de "populismo". La enorme diversidad de movimientos que se han definido como populistas a lo 
largo de la historia plantea una cierta dificultad para encuadrar de forma exacta qué implicaciones y límites tiene este término. El populismo como concepto no responde a una única definición válida, ni a un tipo concreto de político o partido; sino que es un término variable y polisémico, pudiendo ser urbano o rural; progresista o conservador; capitalista o anticapitalista; de masas y de élites; socialista o fascista; de izquierda o de derecha (Freidenberg, 2007). Se ha debatido tanto el término que ya cabe en él un amplio abanico de movimientos que podrían considerarse inside o abarcados por él. Es por ello que en este trabajo no deseamos abrir un nuevo debate sobre el concepto de populismo, que ya ha sido criticado desde numerosos enfoques (Roxborough, 1984; Solari et. al, 1976; Canovan; 1981; Mouzelis, 1985), sino entenderlo como una categoría, que desde su amplitud y abstracta definición podría albergar algunos movimientos políticos que aquí proponemos para ser analizados desde un punto de vista emocional.

El vocablo "populista" se ha empleado para designar a líderes, a los que se cataloga de demagogos, autoritarios, personalistas o decisionistas. También se refiere como populistas a determinados movimientos tildados de irracionales, protagonizado por «masas», pasionales y policlasistas. Pero, además, también se identifica a ciertas políticas como populistas, cuando ellas generan intervenciones en el funcionamiento del mercado, políticas públicas de transferencias de ingresos, estatizaciones de empresas o nacionalizaciones de recursos (Retamozo, 2012). Si una definición cuenta con bastante acuerdo generalizado podría señalarse a aquella que describe al populismo como una particular visión del mundo entendido como resultante de una relación antagónica entre dos constructos homogéneos: el pueblo (bueno), y la élite (mala) (Abts y Rummens, 2007; Mudde,2004, 2007).

Para este trabajo vamos a entender el populismo como una estrategia política (Weyland, 2001), tanto como un modo de identificación y manera de entender la política y la democracia (Panizza, 2011), así como un estilo de liderazgo, caracterizado por la relación directa, carismática, personalista y paternalista entre líder-seguidor (Freidenberg, 2007). En términos globales, consideramos el populismo como un fenómeno político. Bajo esta definición entendemos los movimientos políticos que pueden ser denominados o calificables de "populistas". Méndez (2014:94) efectúa una definición que también se ajusta a los objetivos de este trabajo, pues considera al populismo como "corrientes políticas heterogéneas que movilizan a un gran número de personas, sirviéndose de contenidos emocionales entorno a los conceptos de identidad y autoaformación como pueblo $[\ldots]^{\prime}$.

Pese a referirnos en este trabajo a movimientos populistas del S.XXI, cabe tener presente que estos movimientos, algunos resurgidos desde finales de los 90, principalmente en América Latina, han sido bautizados como "neopopulismos" (Malamud, 2010) en tanto que reencarnación de los movimientos populistas que estuvieron presentes en Brasil, Perú, República Dominicana o Guatemala y que fueron denominados como el "primer populismo". Al neopopulismo se le conoce como el conjunto de ideas que a veces pueden parecer doctrina, en el cual se afirma tener como objetivo primordial la defensa del pueblo, indicando como tal a la población menos favorecida, dentro del entramado socioeconómico y político (Arévalo, 2007).

Pese a que el término populismo siempre tuvo una connotación negativa, Laclau (2005) revierte este hecho al aludir que el populismo comienza allí donde los elementos popular-democráticos son presentados como una opción antagonista contra la ideología del bloque dominante. En este sentido, cabe destacar de entrada la lateralidad y ambigüedad del populismo con respecto del eje izquierda/derecha (Betz e Immerfall, 1998; Taggart, 2000; Mude y Rovira Kaltwasser, 2012:7-10). 
Es decir, que la lógica populista está igualmente presente en polos ideológicos-políticos opuestos (Mény y Surel, 2000).

El neopopulismo o populismo de tercera ola se caracteriza por postulados más radicales en relación a las olas predecesoras. Está marcado por gobiernos populistas de izquierda en Latinoamérica y de derecha e izquierda en Europa, que han buscado elementos identitarios, simbólicos y emocionales. Siguiendo a Dijk (1996), una ideología como el populismo sirve para enmarcar a sus miembros como entes sociales definiendo su pertenencia al grupo (quiénes somos y cómo debería de ser un miembro del grupo), las actividades (lo que se espera de los miembros), las metas (los objetivos últimos del grupo), las normas y los valores (qué es aceptable y no en el grupo), la posición (la relación con el resto de grupos), y los recursos (tanto materiales como simbólicos que permiten al grupo expandirse y protegerse ante otros).

\subsection{El factor emocional en la política}

Las emociones desempeñan un rol evidente y omnipresente en la vida individual y social, por ende, también en la política: miedo ira, culpa, pena, envidia, son algunos de los sentimientos que juegan un papel fundamental en la formación de los movimientos sociales, en la vida de cada ciudadano, así como en la estrategia electoral de los partidos políticos (Cossarini y García, 2015).

La política está impregnada de emociones. Sin embargo, la afectividad no es un factor exclusivo del populismo, ni el populismo se agota en lo emocional. Todas las ideologías, doctrinas y movimientos políticos poseen una dimensión emocional, desplegando un régimen afectivo particular y movilizador de emociones concretas, invistiendo a determinados conceptos o significados igualdad, libertad, tradición, naturaleza, nacionalismo...- (Arias, 2017).

Villacañas (2015) sostiene que el populismo arranca de la convicción de que la sociedad no puede asentarse sobre una base racional. El populismo se dirige a la multitud a través de medios primordialmente emocionales (Arias, 2016). El populismo no ha inventado las emociones políticas, pero sí es aquel estilo político que, por fundarse en un antagonismo fundacional y en una concepción homogénea del pueblo, desafía abiertamente la idea de que las democracias sean construcciones racionales o que aspiran a la racionalidad social (Arias, 2016). O'Donnell (1992), introdujo el término "democracias delegativas", como régimen donde el gobernante decía encarnar al conjunto de la nación, sus anhelos e intereses, sin necesidad de rendir cuenta de sus actos a las otras instituciones del Estado.

\subsubsection{La sentimentalización del mensaje político}

En los últimos años hemos observado una imposición o preponderancia de la cultura de lo emocional, derivado de los estudios neurocientíficos que han ido destacando el protagonismo de las emociones en el comportamiento del ser humano. Efectivamente lo emocional vende mejor, exige menos reflexión y conecta de una manera más fácil con la ciudadanía. Se viene evidenciando en el debate político y en los medios de comunicación un auge por apelar a componentes de tipo afectivo (Arias, 2016). En este sentido comienzan a imperar las lógicas emocionales, de apelación a los afectos para atraer a la ciudadanía a la identificación y fidelidad.

Conocedores del impacto que las apelaciones emocionales conllevan en el electorado, se ha apreciado en los movimientos populistas una proliferación de mensajes efectistas que esgrimen hipotéticas consecuencias (bienestar, felicidad, miedo...etc.), diseñadas para lograr reacciones 
concretas del electorado en un espacio corto de tiempo (Brown, 1991: 7). Al igual, es frecuente, por su gran efecto, el recurso a los mitos de corte nacionalista (patria, historia, destino, lengua, raíz, religión), con la intención de establecer una estrecha vinculación entre valores generales de la sociedad y particulares del partido o líder (Laguna, 2010). De hecho, para convertir a un político en símbolo o icono, se debe recurrir frecuentemente a los valores, tanto ideológicos como experienciales. A ello cabe sumar la fortaleza que asume la alusión o creación de un "enemigo externo", a quien se identifica como causa de todos los males (Ost, 2004:237-238).

Otro factor presente en el discurso emocional es la demagogia, que ha arrastrado hacia sí grandes prejuicios al estar asociada a la estimulación de las ambiciones y sentimientos de la población y, sobre todo, por ser una estrategia de manipulación que esconde promesas irrealizables (Swan, 2009:121). Los más críticos con esta forma de hacer política caracterizada por la exaltación de las pasiones considera que "el exceso de recursos emotivos en el populismo, en detrimento del argumento racional y la actitud crítica, implica una manipulación de las conciencias con formas persuasivas y fondo no democrático" (Charaudeau, 2009: 263-264).

En el discurso emocional juegan un papel muy significativo las metáforas y los marcos mentales. Neurocientíficos reconocidos como Lakoff o Haidt, consideran que las metáforas, las imágenes y otros elementos retóricos constituyen los ejes del comportamiento político, siendo elementos que permiten llegar a las fuentes intuitivas e inconscientes de nuestros juicios morales y políticos (Lakoff, 2009; Ortiz, 2016). Para estos autores, ni la mente ni el lenguaje tienen un contenido objetivo compartido de la misma forma por todo el mundo, sino que sus contenidos cobran sentido siempre dentro de narrativas. Las narrativas, a su vez, se componen de marcos, que son sistemas conceptuales que articulan nuestro pensamiento, permitiendo articular relatos sobre qué es bueno y qué es malo en torno al tema que hace referencia (Pérez-Zafrilla, 2017).

Precisamente una de las estructuras mentales en las que articulamos nuestro pensamiento, según Lakoff, son las metáforas. Éstas son las expresiones o lemas que convierten en moneda común los políticos y, en forma de clichés y etiquetas, encasillan elementos como políticas emprendidas, los adversaros políticos o los defensores de ciertas posiciones. Según Pérez-Zafrilla (2017), la repetición reiterada y constante de la metáfora es lo que permite activar el circuito neuronal en el cerebro del oyente que permite reforzar la sinapsis. De este modo, únicamente con nombrar la metáfora se activa en el público un marco en el que algo se identifica como bueno o malo de una forma no consciente. Los movimientos populistas son muy propensos a narrar mediante historias y relatos (storytelling), circunstancia que facilita generar vínculos emocionales con la ciudadanía. De hecho, si en algo son expertos estos movimientos es en dramatizar crisis, reencuadrar los hechos para imponer sus propias perspectivas y escenificar hipotéticos conflictos entre pueblo y élites.

\subsubsection{La sentimentalización del mensaje político}

Si existen emociones trascendentales a todos los movimientos analizados en el presente trabajo, esas son miedo y entusiasmo. El miedo podría considerarse la emoción más citada por los pensadores políticos a lo largo de la historia. Haciendo un rápido recorrido encontramos a maestros como Cicerón, quien reseñaba que el miedo constituía un arma poderosa para manipular al populus, o Maquiavelo siglos después, que dedica un capítulo en "El Príncipe" al uso del miedo. Hobbes tampoco concebía la política sin el miedo, pues según él constituye el motivo que conduce a la sociedad a crear el Leviatán. Por su parte Spinoza señala al miedo como un aspecto negativo de la vida política y Tocqueville llega a considerar al temor útil como instrumento para la consolidación 
del nuevo sistema (tras dejar atrás el Antiguo Régimen). Para autores más contemporáneos como Robin, Foucault o R. Bernstein, el miedo, lejos de ser un fin en sí mismo, es más bien una herramienta política para lograr el adoctrinamiento interno. Un miedo que puede actuar por medio de un enemigo tanto externo como interno (López, Gil y Molina, 2016).

En efecto, el entusiasmo y el miedo son las emociones más poderosas en política. El miedo nos genera desconfianza, rechazo y oposición hacia unos (los que amenazan) y simpatía, afecto y solidaridad hacia otros (los que protegen). Además, crea un dominio absoluto de las emociones en nuestras relaciones con los demás. El miedo es una reacción individual, pero también colectiva, ante un peligro o una amenaza que genera antipatías, fobias, animadversiones, e incluso, odios políticos, ya que cuando el miedo se impone, las emociones minan cualquier posibilidad de análisis racional (Valdez, et.al, 2009).

La recurrencia a estas dos emociones básicas, positivas (esperanza/entusiasmo) y negativas (miedo/ ira) forman parte del discurso y estrategia de los movimientos políticos que emergen con liderazgos diferenciados y con el deseo de conquistar rápido el poder logrando la movilización del electorado. No podemos olvidar que el control muchas veces opera en clave emocional (Hochschild, 1975), fundamentalmente asentándose en el miedo, pero también generando esperanzas y construyendo ilusiones. Los grupos populistas consideran estar gobernados por gente alejada de la experiencia humana real (casta, élites, enemigos...etc.), capaces de imponer medidas injustas que merman la dignidad de los más desfavorecidos (según populismo de izquierda) o que hacen peligrar la integridad de la nación (populismo de derecha).

Un ejemplo claro del empleo del miedo y la ira lo observamos en los recientes movimientos populistas europeos de extrema derecha, que cuentan con un fuerte discurso anti-inmigratorio y euroescéptico, capaz de propagar alarma social ante lo que consideran una "amenaza" a la integridad de sus países. Movimientos que "beben" del hartazgo hacia la corrupción, a crisis políticas y económicas o a crisis internacionales como los refugiados sirios que buscan asilo en Europa ${ }^{1}$

El populismo de derecha, en auge en Europa en la presente década, es fundamentalmente euroescéptico, y dirige toda su acción a culpar a las instituciones europeas de las problemáticas que asolan en sus países, en algunos casos construyendo falsas amenazas. En esta línea tienden a estigmatizar a los grupos que consideran peligrosos para la sociedad (inmigrantes, homosexuales...). En definitiva, a construir un nacionalismo excluyente. En lo económico se caracterizan por ser liberales con la aplicación de medidas intervencionistas como el proteccionismo. La derecha populista europea es tendente a enfatizar la seguridad frente a la igualdad, y, en algunos casos es tildada de neonazi y violenta.

Para afianzar identidades y lealtades políticas, el populismo sabe de la necesidad de estereotipar y etiquetar, a fin de generar enemigos. Esta circunstancia permite crear comunidad e identidad hacia una causa, que se revela contra otra, y así se reconforta. En esta línea, como apunta Freidenberg (2007: 34), el populismo cuando apela constantemente al pueblo, está eliminando al individuo como sujeto del discurso y fundiéndolo en un colectivo.

${ }^{1}$ Bajo el término de extrema derecha populista (o nacionalpopulismos), pueden considerarse a formaciones políticas europeas, de relevancia variable. Destacan: el Frente Nacional francés, el UKIP británico, la Liga Norte italiana, el Law an Order polaco, el Partido de la Libertad de Austria, Partido de la Libertad de Holanda, los Verdaderos Finlandeses, Amanecer Dorado en Grecia, Alternative for Germany, el Movimiento por una Hungría Mejor, el Partido por la Libertad en Holanda, los Demócratas de Suecia y el Partido Popular Suizo, entre otros. 
El corazón del discurso populista no es únicamente la apelación al pueblo, como colectivo, sino que resulta preciso hacer oposición a otra cosa para potenciar la diferencia, esto es, presentar al pueblo como antagónico a otro sujeto. En este sentido, la construcción del antagonismo entre pueblo y élite se apoya sobre un conjunto de mecanismos psicológicos y afectivos que remiten a los déficits de racionalidad del sujeto político (Arias, 2017).

Los políticos saben que cuanto menos se traten los temas y más simples sean los enunciados, más fácil será captar la atención y conseguir la reiteración que facilite su recuerdo (Izquierdo,1975). Este es un recurso muy dado entre los políticos populistas, y/o neopopulistas. Es muy habitual encontrar en ellos apelaciones al miedo, esencialmente al cambio, con una tendencia a la demonización de la oposición (y a organismos internacionales), incluso acuñándoles hipotéticas acciones destructoras que ejecutarían si llegaran al poder y que, en muchos casos, tienen que ver con logros conseguidos, creencias y valores compartidos, status quo...etc. Estudios recientes sobre los movimientos sociales han demostrado que la ira motiva y da energía a las luchas colectivas por la justicia (Goodwin et al., 2001; Jasper, 1999). En efecto el miedo es una emoción muy potente en política y se observa muy presente como recurso retórico para sustentar el poder, también en sistemas democráticos. Un miedo que en este caso lo diferenciamos de la sumisión, opresión, control, dominación, coacción o amenaza, tan presente a lo largo de la historia como políticas de Estado de regímenes no democráticos.

\subsection{El factor emocional en la política}

A medida que se ha ido desarrollando el márquetin político y profesionalizándose los medios de comunicación, especialmente la televisión, se ha ido virando hacia un protagonismo mayor de los líderes políticos en detrimento de sus partidos, que quedan relegados como plataformas de apoyo que sirven de organización y movilización. Esta tendencia a la personalización de la política ha sido importada de los mercados políticos estadounidenses, donde la televisión lo cambió todo (Salgado, 2002). Efectivamente la televisión ha posibilitado que los líderes puedan dirigirse a los votantes de manera directa, sin la intermediación de los partidos y sus militantes. En este contexto, divertir, emocionar y provocar, entre otras sensaciones, tendrá mayores efectos en la audiencia que argumentar, razonar o explicar algo tan complejo y distante como la política (Laguna, 2010). Esta personalización de la política que efectúan los medios masivos de comunicación, junto con el protagonismo que juega el líder en la oferta electoral (naturalmente más notable en sistema presidencialistas), desembocará de forma natural en un tipo de voto centrado en el candidato o candidata, su imagen y sus propuestas (García-Beadoux y D’Adamo, 2004: 10).

En ocasiones, el líder populista mezcla un diagnostico bastante ajustado de la realidad con una esperanza emotiva para los seguidores (Freidenberg, 2007). Estos liderazgos de políticos populistas suelen adoptar características y estilos propios que les diferencia del resto de políticos y que van desde expresiones, formas de hablar, de comunicar, estilos musicales e incluso características de la vestimenta. A diferencia de los europeos, los movimientos latinoamericanos se han caracterizado por formas de vestir y actuar que buscaban una conexión con el "pueblo" con la finalidad de llegar a aquellos que sienten que no tienen voz en el sistema político (Panizza, 2011).

El populismo, desde el estudio clásico de Laclau, se ha entendido como la simplificación del discurso político en términos de buenos y malos, de pueblo justo frente al poder injusto (Laguna, 2010). Como el profesor Caplan (2006) asegura, las ideas populistas son difíciles de erradicar porque hay una conexión emocional con ellas que hace que la gente se sienta bien apoyándolas. Precisamente una de las características de este tipo de movimientos o liderazgos políticos, bien 
apuntada por Delsol (2016), es que no suelen tener una teoría argumentada sino una idea general sobre cómo vivir bien mientras que el jefe se convierte en su teoría viviente por la confianza que le depositan. En todos los movimientos populistas reside un discurso de carácter fuertemente emocional donde subyace la idea del pueblo como el depositario de las virtudes sociales de justicia y moralidad (González Calleja, 2002). De hecho, como señaló Worlsey (1969), el populismo tiene como elemento central la noción de supremacía del pueblo y la relación directa entre dicho pueblo y el Gobierno.

El éxito populista radica en la habilidad del líder carismático de entender la relación patronal y crear un parentesco entre él y los seguidores, ya sea a través de su discurso, los mensajes vía medios de comunicación o gracias a los contactos personales (Freidenberg, 2007). Para lograr este cometido, los líderes populistas emplean una retórica emocional que como hemos citado se sustenta en la esperanza y miedo. Por lo general todos son coincidentes en tipos de liderazgos caracterizados por la valentía, actuando con decisión y firmeza en los planteamientos que esbozan, incluso en aquellos más radicales o complejos (regulación de inmigración, reformas constitucionales, referéndums, salidas de organismos internacionales...etc.). En ocasiones, este tipo de líderes anuncian medidas que son difícilmente rechazables puesto que nadie se opone a que las personas tengan todo lo que necesitan. Así, líderes de incuestionable raíz democrática por haber ganado las elecciones, que abrazan la defensa de la nación como principal seña de identidad, basan su liderazgo en vincular la idea emotiva de la patria con su propia persona (Laguna, 2010:80). Otra de sus idiosincrasias es la capacidad de dividir entre pueblo virtuoso y élite corrupta. En ocasiones planteando la disolución de fronteras y antagonismos internos de clase e identidad en favor de la construcción de un sujeto popular transversal en clave de nación.

En suma, asistimos a un liderazgo personalista y sensacionalista, puramente emocional, caracterizado por una movilización de personas para que realicen lo que se considera que tienen que hacer. Esta movilización suele partir de lo positivo (amor y justicia) o desde lo negativo (miedo e ira). El líder populista regula y controla los sentimientos y emociones de las multitudes, siendo capaz de llevar a la catarsis colectiva con sus palabras, de apaciguar los ánimos y controlas las pasiones aludiendo al imaginario colectivo, a la identidad nacional y a la visión maniquea de la vida entre amigos y enemigos; en suma, asumiendo la redención del pueblo (Guariglia, 2011:65).

Llegados a este punto es preciso destacar el desarrollo de la telegenia de estos políticos. Las televisiones se han convertido en las principales plataformas audiovisuales para ser reconocidos y persuasivos. En este sentido, Domínguez (1983: 144), asegura que los consumidores de televisión no votan a un candidato por lo que dice, sino que "lo compran psicológicamente", por cómo lo dice. En este contexto, aspectos comunicacionales como la parte no verbal y la paraverbal, asumen mayor protagonismo que el discurso mismo (la comunicación verbal). El profesor Martín Serrano (1982:71), explicó que los estudios de comportamiento electoral de las audiencias demuestran que "los teleoyentes son proclives a sustituir el análisis de la realidad política por la respuesta emotiva; el compromiso con un programa, por la transferencia afectiva de un guía carismático". El medio televisivo transmite con más facilidad y eficacia las emociones que los conceptos (Laguna, 2010). Esto se debe, fundamentalmente, a que la televisión proyecta en nuestro cerebro la imagen del candidato, sin el deber de realizar ningún esfuerzo cognitivo.

\subsubsection{Carisma}

El marcado personalismo de la política hoy es también un factor que facilita el desarrollo del populismo. Con el desarrollo de la televisión, los candidatos/as pueden entrar en todos los 
hogares y comunicar directamente al votante sus ideas, lo que a su vez crea la necesidad de líderes carismáticos y telegénicos, con historias personales que apelen al electorado (Rodríguez, 2012). A diferencia de los líderes racional-burocráticos, el liderazgo carismático está sustentado en una entrega y reconocimientos de los seguidores hacia él. Aunque la emoción ha sido percibida dentro de la tradición racionalista como un obstáculo que perturba el curso normal de las conductas (Dorna, 2006), la psicología del liderazgo ha demostrado la interacción que se da entre aspectos racionales y emocionales (Freidenberg, 2007).

Teóricos de la escuela tradicional del populismo como Germani (1971), Di Tella (1977) o Paramio (2006), consideran que el populismo implica la irrupción de las masas populares en la política mediante la exaltación de un líder carismático que las utiliza para su propio beneficio. Para esta escuela de pensamiento, asume una gran relevancia la estrategia que emplean ciertos liderazgos políticos para llegar al poder, pese a que ello implique el desmantelamiento de las instituciones democráticas. Una estrategia que pasa por la exaltación de las masas a partir de un liderazgo carismático y demagógico.

Una de las características de los liderazgos populistas es generalmente el carisma del líder o la líder. Es decir que la naturaleza del liderazgo populista está condicionada por la presencia de cierta dosis de carisma (Freidenberg, 2007). Sin un líder que tenga "don de gracia” (Weber, 1922), es muy difícil -no imposible- encontrar un liderazgo populista. De hecho, como apunta Arias (2017:154), "los partidos populistas no son los únicos liderados por personalidades carismáticas: sin lo primero no hay populismo, sin lo segundo puede haberlo". Entre los rasgos carismáticos que integran el liderazgo populista cabe destacar su perfil estrictamente personal (marcado personalismo), que no está sujeto a normas, códigos y regulaciones, por ello actúa libremente, rompiendo lo establecido y vendiéndose como un revolucionario. Por lo general suelen ser buenos comunicadores y gozan de voceros (discípulos y seguidores) que trabajan en pro de incrementar la devoción y entusiasmo hacia el líder. En base a lo anterior, mediante vínculos personales y afectivos, se va construyendo lazos de lealtad entre seguidores y el propio líder.

En palabras de Di Tella (1977: 47), el líder carismático debe tener "la capacidad de convertirse en palabras sagradas, objeto de un credo". Ese carisma en ocasiones requiere de toques de mesianismo a fin de lograr la fidelización de las voluntades. El mesianismo es un atributo temperamental, incluso un talento que muestran algunos individuos para generar visiones proféticas trascendentales o mundanas. Cabe entendido, además, como la capacidad de arrastre de acólitos dispuestos a los mayores sacrificios (Tobeña, 2017). Para el autor, detrás de los movimientos doctrinales con gran capacidad de arrastre colectivo no falta jamás un líder carismático.

Dorna (2006) habla de una cuádruple identificación de mecanismos que convierten al líder carismático en un agente de cambio y de transformación: la inspiración, dado que motiva a los miembros del grupo a superarse gracias a las cualidades del conjunto; la consideración, puesto que motiva a los miembros del grupo a la movilización: la gratificación en tanto que el líder recompensa las actitudes y comportamientos de cambios de valores y de creencias que experimentan sus seguidores y, por último, la identificación, representando el líder la encarnación del proyecto colectivo y la adhesión a las mayorías. En definitiva, el populismo se apoya en el liderazgo carismático de sus representantes, en sus cualidades comunicativas y en la vinculación emocional entre líderes y seguidores, pasando por los mitos simbólicos y ritos identificativos (gestos, vestimentas, proclamas, cánticos...etc.) que sostienen esa relación. 


\section{Resultados}

Cuando en este trabajo aludimos a movimientos populistas o neopopulistas, lo hacemos identificando una serie de variables e ítems que las integran (ver tabla 2), que a nuestro juicio aguardan una dimensión o trasfondo emocional en todos ellos (H1). Esas variables nos permiten identificar, con mayor o menor grado de penetración, a movimientos como los reflejados en la tabla adyacente. No obstante, es preciso reseñar que en esta investigación no procedemos a la medición, sino a establecer una propuesta de clasificación operativa de características.

Tabla 1. Movimientos políticos populistas y neopopulistas en Europa y América Latina, siglo XXI. Fuente: Elaboración propia.

\begin{tabular}{|l|l|l|l|}
\hline $\begin{array}{l}\text { Primera década } \\
\text { del S.XXI } \\
(\mathbf{2 0 0 0 - 2 0 1 0 )}\end{array}$ & Periodo & $\begin{array}{l}\text { Segunda década } \\
\text { del S.XXI } \\
\mathbf{( 2 0 1 0 - a c t u a l i d a d )}\end{array}$ & Periodo \\
\hline $\begin{array}{l}\text { Chavismo (Vene- } \\
\text { zuela) }\end{array}$ & 1999-actualidad & $\begin{array}{l}\text { Marine Le Pen } \\
\text { (Francia) }\end{array}$ & 2011-actualidad \\
\hline $\begin{array}{l}\text { Lulismo } \\
\text { (Brasil) }\end{array}$ & $2003-2015$ & $\begin{array}{l}\text { Beppe Grillo } \\
\text { (Italia) }\end{array}$ & 2013-actualidad \\
\hline $\begin{array}{l}\text { Kirchnerismo (Ar- } \\
\text { gentina) }\end{array}$ & $2003-2015$ & $\begin{array}{l}\text { Pablo Iglesias } \\
\text { (España) }\end{array}$ & 2014-actualidad \\
\hline $\begin{array}{l}\text { Berlusconi } \\
\text { Italia) }\end{array}$ & $2008-2012$ & $\begin{array}{l}\text { Alexis Tsipras } \\
\text { (Grecia) }\end{array}$ & 2014-actualidad \\
\hline $\begin{array}{l}\text { Rafael Correa (Ecua- } \\
\text { dor) }\end{array}$ & $2007-2017$ & $\begin{array}{l}\text { Fidesz-Unión Cívica } \\
\text { Húngara } \\
\text { (Hungría) }\end{array}$ & 2010-actualidad \\
\hline $\begin{array}{l}\text { Evo Morales } \\
\text { (Bolivia) }\end{array}$ & 2006 -actualidad & & \\
\hline
\end{tabular}

Naturalmente nada tiene que ver el populismo antiamericano, procubano, socialista y los "consejos comunales" de Chávez con las medidas educativas y urbanísticas de Lula Da Silva a favor de las favelas a la vez que participa de una economía de mercado (Charaudeau, 2009: 255-260). Tampoco tienen ideas en común Marine Le Pen con Evo Morales o bien Pablo Iglesias con Berlusconi, verbigracia. Sin embargo, a nuestro juicio, estos movimientos, por alguna, varias o todas las dimensiones de análisis que proponemos, comparten una base de carácter emocional que estamos tratando de evidenciar este trabajo, al margen de sus ideologías y las características programáticas de unos y otros. Un uso, recurso y esencia de lo emocional que refuerza las teorías que ponen de manifiesto el protagonismo de las emociones en la política. 
Citábamos con anterioridad el carácter euroescéptico y anti-inmigración de la derecha populista europea, así como su marcado antielitismo. La izquierda populista, por su parte, si bien es igualmente antielitista, antepone la defensa de la igualdad y de la justicia social. Es decir, el patriotismo conservador de unos, frente al patriotismo "social" de los otros sustentado en la demagogia y juego de emociones, que pasa por la identificación y demonización de unos adversarios y una reconstrucción de la realidad. Al margen de las diferencias ideológicas de un tipo y otro de populismo, encontramos más allá de lo programático características que permiten demostrar la conexión emocional de esta forma de hacer política con la ciudadanía. En la siguiente tabla, hacemos una propuesta en función de las cuatro dimensiones señaladas en la metodología, con especial ahínco en el estilo de liderazgo y la retórica empleada.

Tabla 2. Propuesta de clasificación e identificación de cualidades y características de los movimientos políticos populistas y neopopulistas. Fuente: elaboración propia inspirado en características extraídas de los trabajos de Freidenberg (2007), Malamud (2010) y Hermet, Loaeza y François (2001)

\begin{tabular}{|c|c|}
\hline 1. Procedencia y contexto & $\begin{array}{l}\text { 2. Su relación con la democracia } \\
\text { representativa }\end{array}$ \\
\hline $\begin{array}{l}\text {-Surgen como reacción o consecuencia de } \\
\text { crisis económicas y/o auges de desafección } \\
\text { política (desesperanza, necesidad, enfado...) } \\
\text {-Surgen en sistemas de partidos débilmente } \\
\text { institucionalizados o partidos poco organi- } \\
\text { zados } \\
\text {-Emanan de las clases populares (generalmente } \\
\text { populismos de izquierda) } \\
\text {-Emanan de las élites económicas (generalmen- } \\
\text { te populismos de derecha) }\end{array}$ & $\begin{array}{l}\text {-Se vanaglorian de ser los auténticos "demó- } \\
\text { cratas" y de ser "el pueblo" } \\
\text {-Cuestionan o critican los fallos de las insti- } \\
\text { tuciones de la democracia representativa } \\
\text {-Apelaciones constantes a la soberanía y } \\
\text { voluntad del pueblo } \\
\text {-Demandan más formas directas de demo- } \\
\text { cracia participativa (referéndums, plebiscitos, } \\
\text { consultas...) } \\
\text {-Líder antipartido } \\
\text {-Lideran su propio partido o movimiento } \\
\text {-Recuperan los mitos fundacionales (padres } \\
\text { fundadores, libertadores...) } \\
\text {-Se autodefinen como anti establishment } \\
\text { político y/o anti oligarquías económicas } \\
\text {-Proponen la refundación de la nación en } \\
\text { términos democráticos y/o jurídicos } \\
\text {-Se observa una demonización de la oposi- } \\
\text { ción, con constantes apelaciones al miedo } \\
\text {-Hacen uso del antagonismo moralista de } \\
\text { "pueblo" frente a "élite" } \\
\text {-Son partidarios de una democracia de corte } \\
\text { agonista }\end{array}$ \\
\hline
\end{tabular}




\begin{tabular}{|c|c|}
\hline 3. Estilo de liderazgo & 4. Retórica \\
\hline $\begin{array}{l}\text {-Líder carismático/a, personalista y paterna- } \\
\text { lista } \\
\text {-Habla en nombre del pueblo y no reconoce } \\
\text { mediaciones organizativas } \\
\text {-Proyectan aires mesiánicos } \\
\text {-Son demagógicos } \\
\text {-Su liderazgo logra movilizar a las masas } \\
\text {-Se venden como revolucionarios } \\
\text {-Hay uso de antagonismos políticos (enemi- } \\
\text { gos, nosotros contra ellos...etc.) } \\
\text {-Emplean formas de vestir no convenciona- } \\
\text { les que rompe con la formalidad asociada a } \\
\text { las “élites” } \\
\text {-Poseen buenas dotes comunicacionales } \\
\text {-Son propensos a comunicar constantemente } \\
\text { su mensaje ya sea en medios de comunica- } \\
\text { ción o redes sociales } \\
\text {-Desarrollan un liderazgo provocador, pola- } \\
\text { rizador e incitador a la protesta } \\
\text {-Construyen una performance global que } \\
\text { incluye ideas, vocabulario, lenguaje corporal, } \\
\text { gestos y atuendos. }\end{array}$ & 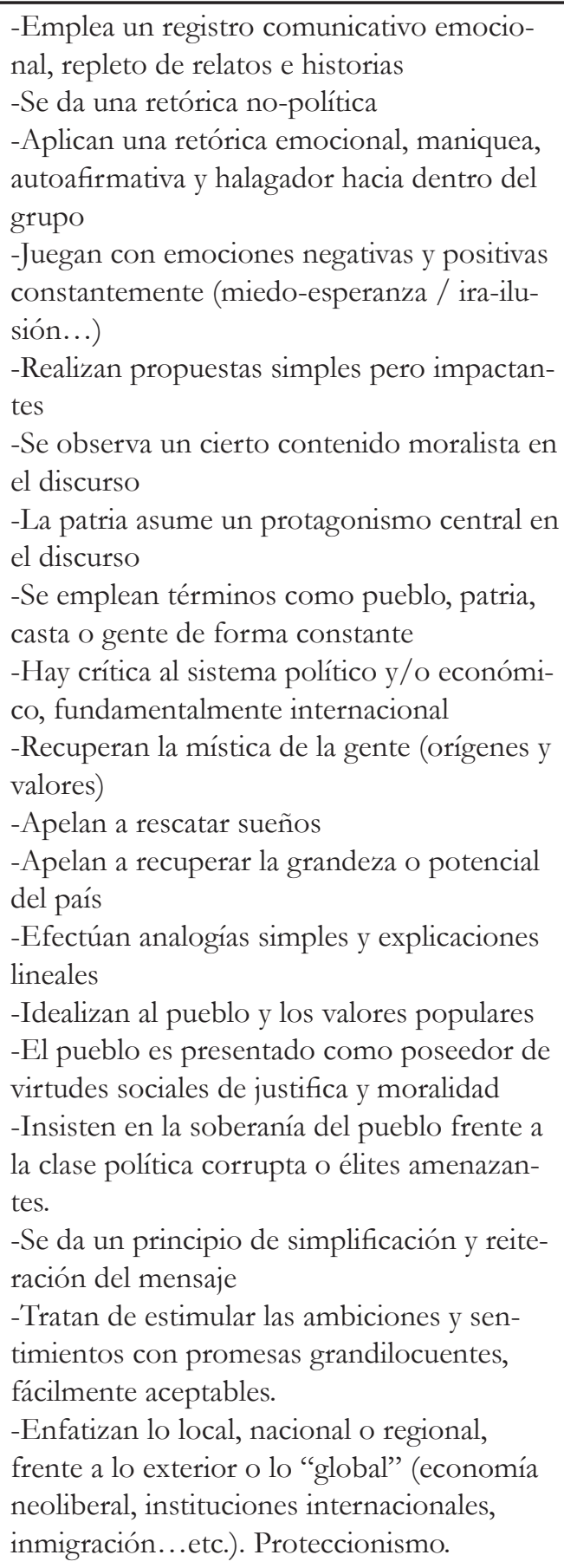 \\
\hline
\end{tabular}




\section{Discusión y conclusiones}

Partíamos en este trabajo planteándonos como pregunta de investigación si las emociones están presentes en los movimientos populistas, algo que nuestro trabajo ha demostrado como certero. También nos preguntábamos cómo integran en esas emociones en sus formas de comunicar e interpretar la democracia. Para ello hemos establecido la clasificación operativa de características que nos ha permitido ir explorando en profundidad la idiosincrasia populista, en su vertiente emocional.

Nuestro trabajo plasma numerosas características fácilmente atribuibles a los diferentes movimientos populistas, destacando el hecho de presentarse como una élite anti statu quo, el funcionamiento en apariencia deficiente de las instituciones de representación política, una ideología de movilización y una relación entre un líder carismático y unas masas disponibles (Prud'homme, 2001). Así, el trabajo, en términos cualitativos efectúa un retrato por la dimensión emocional que esencia e inunda a los movimientos populistas latinoamericanos y europeos surgidos en el presente siglo y que, fundamentalmente, se observa por el tipo de liderazgo que desarrollan y la retórica que los acompaña. Un estilo de liderar, comunicar y gestionar la res publica donde la simplificación, la movilización emocional, y la confrontación se anteponen a las formas convencionales de hacer política.

Adicionalmente, nuestro trabajo concuerda en esencia con los diferentes enfoques o escuelas académicas desarrolladas sobre el populismo, compartiendo una serie de características que los identifica (Mudde y Rovira, 2012): 1) hay cierto consenso en que el populismo necesita ciertas condiciones para surgir, como crisis políticas, de representatividad y económicas; 2) surge como un reclamo a la democracia existente, que se fortalece por el descrédito a los actores políticos; 3) requiere de uno o varios liderazgos que elaboren una identidad-otredad que polarice entre "el pueblo" y la "élite" y , 4) no tiene una ideología característica.

Aunque el término populismo carece de precisión científica y padece una ambigüedad estructural, en este trabajo nos hemos propuesto acercarnos de la forma más rigurosa posible a la descripción de un conjunto de movimientos políticos dados en el presente siglo, en América Latina y Europa, y que comparten una serie de características, destacando fundamentalmente su marcada transcendencia emocional. No es pretensión de este trabajo ahondar en diferencias entre populismos de izquierdas y de derechas o entre populismos latinoamericanos y europeos. De hecho, sería fácil encontrar similitudes y diferencias, por ejemplo, si atendiéramos a otros ítems como el gasto público, el contexto, o medidas programáticas como la demanda de mayores mecanismos plebiscitarios para democratizar los sistemas políticos y sondear acerca de la permanencia en organismos internacionales. Además, hay corrientes que prefieren no etiquetar de derecha o izquierda al populismo y optan por denominarlo populismo reactivo frente a populismo emancipador, respectivamente (Cadahia, 2007).

El populismo del siglo veintiuno, en definitiva, tiene mucho de emoción y poco de razón. Estos movimientos, en sus diferentes vertientes, han demostrado una gran capacidad para manipular las mentes y acciones de sus seguidores, con reinterpretaciones de la realidad, encuadres interesados de los problemas y las políticas públicas. Así, liderazgos carismáticos y personalistas capaces de despertar los sentimientos más primarios, cuestionamientos del funcionamiento democrático, retóricas maniqueas y autofirmativas e idealización constante 
del pueblo, constituyen algunas de las características detalladas en las cuatro dimensiones de análisis propuestas que abordan ampliamente el modo de comportarse de estos movimientos políticos tan teorizados.

El ser humano necesita mitos, relatos identitarios, referentes y sentimientos de pertenencia. Generamos identidades políticas que afianzamos con fuertes lazos emocionales hacia ideas o partidos. En definitiva, las emociones son inherentes a los seres humanos y, por tanto, no van a desaparecer de la política. Los populistas son maestros para enfatizar esas uniones pasionales, que logran aparcar la capacidad de reflexión y sumar a sus causas adeptos, que, en ocasiones, quedan cegados de capacidad crítica. Pero hemos de tener presentes que "cuando la política es solo pasión y emoción, la probabilidad de que la tensión social aparezca y el invento de la convivencia democrática quede hecha añicos es muy elevada. Pero pretender, consciente o inconscientemente, que la política esté despojada de pasión y emoción es poner las bases para un proceso de liquidación social de la política” (Sánchez, 2007).

Esta investigación concluye confirmando que no todos los populismos son iguales, ni conducen a resultados similares. De hecho, el trabajo efectuado por Garciamarín, (2018) que compara el populismo latinoamericano con el asiático, concluye en la misma línea. Sin embargo, sí existen características comunes, asentadas en la movilización y apelación emocional, que nos permiten descubrir la dimensión afectiva que caracteriza a los diferentes populismos europeos y latinoamericanos. En futuros trabajos se podría profundizar más sobre cada una de las cuatro categorías de análisis propuestas en esta investigación, e incluso hacer análisis en profundidad de movimientos populistas concretos en base a su dimensión afectiva.

\section{Bibliografía}

Abts, K. y Rummens, S. (2007). Populism versus Democracy, Political Studies, 5, N. 2, pp.405-424.

Arévalo, G. (2007). Economía y neopopulismo en la región Andina. Via Iuris, 4, pp. 139-147.

Arias, M. (2016). La democracia sentimental: politica y emociones en el S.XXI. Barcelona: Página Indómita.

Arias, M. (2017). Las bases afectivas del populismo. Revista Internacional de Pensamiento Político. I Época, 12, pp.151-167.

Betz, H. G., y Immerfall, S. (1998). The New Politics of the Right. Neo-Populist Parties and Movements in Established Democracies, Nueva York, St. Martin's Press.

Brown. J.A. (1991). Técnicas de persuasión. Madrid: Alianza Editorial.

Cadahia, L. (2017). Amor y Emancipación: apuntes para el debate populista. La Circular. 
Calleja, E. G. (2002). Populismo. En Fernández, J \& Fuentes, J.F (ed.) Diccionario político y social del siglo XIX español. Madrid, Alianza Editorial.

Canovan, M. (1981). Populism. Londres: Juction Books.

Caplan, B. (2006). The myth of the rational voter: why democracies choose badpolicies. Princeton: Princeton University Press.

Charaudeau, P. (2009). Reflexiones para el análisis del discurso populista. Discurso y Sociedad, 3 (02), pp. 253-279.

Cossarini, P. y García, R. (2015). El papel de las emociones en la teoría democrática. Desafíos para un uso público de la razón en tiempos de populismo. Revista de Estudios Políticos, 168, pp. $291-315$

Delsol, C. (2016). Populismos: una defensa de lo indefendible. Barcelona: Ariel.

Di Tella, T. (1977) "Populismo y reformismo”. En Germani, G., Ianni, O., y Torcuato D. T (ed.). Populismo y contradicciones de clase en Latinoamérica. México: Era (Serie Popular).

Domínguez, J. (1984). Cómo vender a un candidato. El producto político en el mercado electoral venezolano. Nueva Sociedad, 68, septiembre-octubre, 147.

Dorna, A. (2006). La psicología política: un enfoque heurístico y un programa de investigación sobre democracia. Liberabit. Lima (Perú) 12, pp. 21-32.

Forgas, J. P. (2000). Feeling and thinking: the role of affect in social cognition. Cambridge: Cambridge University Press.

Garciamarín, H. (2018). Populismo en el siglo XXI: un análisis comparado entre Asia y América Latina (Tailandia, Corea del Sur, Venezuela y Bolivia). Revista Mexicana de Ciencias Políticas y Sociales, 233.

Germani, G. (1971) Política y sociedad en una época de transición: de la sociedad tradicional a la sociedad de masas. Buenos Aires: Paidós. 
Freidenberg, F. (2007). La tentación populista. Una vía al poder en América Latina. Madrid: Síntesis

Goodwin, J.; Jasper, J. M., y Polletta, F. (2001). Passionate politics: emotions and social movements. Chicago: University of Chicago Press.

Guariglia, O. (2011). La Democracia en América Latina: la alternativa entre populismo y democracia deliberativa. Isegoría, (44), pp. 57-72.

Gratius, S. (2007). The "Third Wave of Populism" in Latin America . Madrid: FRIDE.

Haidt, J. (2001). The emotional dog and its rational tail. A social intuitionist approach to moral judgement. Psychological Review, 108, pp. 814-834.

Hermet, G., Loaeza, S. y François, J. (comps.) (2001). Del populismo de los antiguos al populismo de los modernos. México: El colegio de México.

Hochschild, A.R. (1975). The Sociology of Feeling and Emotion: Selected Possibilities. En Millman, M.; Kater, R.M. (ed.). Another Voice. Feminist perspectives on social Life and Social Science. Nueva York: Anchor Books, cap. 10, pp. 280-307.

Jasper, J. M. (1999). The art of moral protest culture, biography, and creativity in social movements. Chicago: University of Chicago Press.

Lakoff, G. (2009). The political mind. A cognitive scientist guide to your brain and its politics. Nueva York: Penguin Book.

Laclau, E. (2005). La rąón populista. Buenos Aires y México: FCE.

Laguna, A. (2010). Las claves del éxito político. ¿Por qué votan los ciudadanos? Barcelona: Península.

López, C., Gil, I. y Molina, D. (2016). La política y el poder de las emociones. Comunicación presentada en el XII Congreso Español de Sociología. GT 38, sociología de las emociones.

Izquierdo, F. (1975). La publicidad política. Cómo se convierte a un hombre en candidato. Barcelona: Oikos-Tau. 
Malamud, C. (2010). Populismos latinoamericanos. Los tópicos de ayer, de hoy y de siempre. Oviedo: Nobel.

Martín, M. (1982). La influencia social de la televisión (II). Revista de Investigaciones Sociológicas, 17. Madrid, enero-marzo de 1982.

Méndez, S. (2014). La imagen emocional de Latinoamérica en la presa digital española: Elpais. com como estudio de casos. Revista Faro, vol.1, n 19, pp. 93-112.

Mény, Y., y Surel, Y. (2000). Par le peuple, pour le peuple: le populisme et les de'mocraties. Paris: Fayard.

Mouzelis, N. (1985). Populismo y clientelismo como modos de incorporación de las masas en sistemas políticos semiperiféricos. En Vilas, C. M. (comp). La democratización fundamental. El populismo en América Latina. México: Consejo Nacional para la Cultura y las Artes.

Mudde, C. (2004). The Populist Zeitgeist. Government and Oposition,Vol 39: 542-563.

Mudde, C. (2007). Populist radical right parties in Europe. Cambridge: Cambridge University Press. Mudde, C., y Rovira Kaltwasser, C. (eds.) (2012). Populism in Europe and the Americas: Threat or Corrective for Democracy?. Cambridge: Cambridge University Press.

Ost, D. (2004). Politics as the Mobilization of Anger: Emotions in Movements and in Power. Eropean Journal of Social Theory, 7, 2, pp. 229-244.

Panizza, F. (2011). ¿¿De qué hablamos cuando hablamos de populismo? «iMás populista será tu abuela!». Revista de Ciencias Sociales de la Universidad Católica del Uruguay (RECSO), vol.2, 15-37.

Paramio, L. (2006). La izquierda y el populismo. En Herrero, P. (eds.) La "iqquierda" en América Latina. Madrid: Pablo Iglesias, pp. 21-46.

Pérez-Zafrilla, P.J. (2018). Marcos mentales: ¿marcos mentales? Deloberación política y democracia en la neuropolítica. Revista de Pensament i Anaìsi, 22, pp.91-110.

Prud'homme, J. (2001). Un concepto evasivo: el populismo en la ciencia política. En G. Hermet, J. Prud'homme \& S. Loaeza (Eds.). Del populismo de los antiguos al populismo de los modernos (pp.3265). México D.F: El Colegio de México. 
Retamozo, M. (2012). Democracias y populismos en América del Sur: Otra perspectiva. Un comentario a «La democracia en América Latina: la alternativa entre populismo y democracia deliberativa» de Osvaldo Guariglia. ISEGORÍA. Revista de Filosofía Moral y Politica, 47, juliodiciembre.

Rodríguez, R. (2012). Los efectos de la "americanización” de las campañas electorales en el mundo. Tribuna Norteamericana, 8, pp. 28-38.

Roxborough, Ian. (1984). Unity and Diversity in Latin American History. Journal of Latin American Studies, 16, pp. 1-26.

Sánchez, J. (2007). Cuando la política ya no emociona. Tribuna en El País, 10/09/2017.

Solari, A., Franco, R. y Jutkowitz, J. (1976). El tema del populismo. En Teoría, acción social y desarrollo en América Latina. México: Siglo XXI Editores.

Swan, R. (2009). El método Obama. Las 100 claves comunicativas del hombre que ha revolucionado el mundo. Barcelona: Debolsillo.

Taggart, P. A. (2000). Populism (vol. 3). Buckingham: Open University Press.

Tobeña, A. (2017). Neuropolitica. Toxicidad e insolvencia de las grandes ideas. Barcelona: EDLibros.

Valdez, A., Esparza, M.A., Verara, A. y Cruz, G. (2009). Campañas de contraste en Sistemas Democráticos. México: Prometeo Editores.

Villacañas, J.L. (2015). Populismo. Madrid: La Huerta Grande.

Weber, M. (1922). Economía y sociedad. Esbozo de sociología comprensiva. Madrid: Fondo de Cultura Económica.

Weyland, K. (2001). Clarifying a Contested Concept. Populism in the Study of Latin American Politics. Comparative Politics 34 (1), pp. 1-23.

Worsley, P. (1969). The concept of populism. En G. Ionescu, \& E.Gellner (Eds.), The concept of populism (pp.154-160). Londres: Macmillan. 
MHCJ no 10 (1) | Año 2019 - Artículo no 5 (140) - Páginas 101 a 121 - mhjournal.org

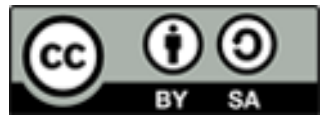

Licencia Creative Commons

Miguel Hernández Communication Journal mhjournal.org

\section{Cómo citar este texto:}

Alejandro Espí Hernández (2019): La dimensión emocional de los movimientos políticos populistas de S.XXI en América Latina y Europa, en Miguel Hernández Communication Journal, nº10 (1), pp. 101 a 121. Universidad Miguel Hernández, UMH (Elche-Alicante). DOI: http://dx.doi.org/10.21134/mhci.v10i0.277 